\title{
PEMANFAATAN TEKNOLOGI TEPAT GUNA KOMPOR ROKET DENGAN FORMULASI BAHAN BAKAR PELET KAYU DAN KAYU SENGON
}

\author{
Oleh : \\ Nurdi Ibnu Wibowo \\ Widyaiswara Madya BBPPMPV Pertanian
}

\begin{abstract}
Abstrak
Kompor roket merupakan kompor tungku yang terbuat dari besi dengan bentuk yang seperti cerobong asap yang memerlukan bahan bakar kayu. Akan tetapi, bahan bakar kayu akan habis jika digunakan terus menerus. Penelitian ini menggunakan pelet kayu dan limbah kayu sengon sebagai bahan bakar kompor roket. Penelitian ini dilaksanakan di Serpong Desa Wangunjaya Cugenang-Cianjur menggunakan Response Surface Methode (RSM) dengan lima formulasi, yaitu F1 (pelet kayu 100\%), F2 (pelet kayu 75\% kayu sengon 25\%), F3 (pelet kayu $50 \%$ kayu sengon $50 \%$ ), F4 (pelet kayu 25\% kayu sengon 75\%), dan F5 (kayu sengon 100\%). Hasil penelitian menunjukkan formulasi F3 memberikan pengaruh yang lebih baik dengan lama nyala api yaitu 19,10 menit dan tinggi api setinggi $35 \mathrm{~cm}$. Sedangkan untuk parameter suhu ruang bakar, pengaruh terbaik diperoleh dari formulasi $\mathrm{F} 1$ dengan suhu $87.2^{\circ} \mathrm{C}$.
\end{abstract}

Kata Kunci : Kompor Roket, Pelet Kayu, Kayu Sengon, Teknologi Tepat Guna, Bahan Bakar Alternatif.

\begin{abstract}
Rocket stove made of iron with a chimney-like shape that requires wood as its fuel. Woods will run out eventually if continuously used as fuel. This research used wood pellets and sengon wood waste as rocket stove fuel. This research was conducted in Serpong Wangunjaya Village Cugenang-Cianjur using Response Surface Method (RSM) with five formulation of fuel, namely F1 (wood pellet 100\%), F2 (wood pellet 75\% sengon wood 25\%), F3 (wood pellet 50\% sengon wood 50\%), F4 (wood pellet 25\% sengon wood 75\%), and F5 $(100 \%$ sengon wood). The results showed that F3 formulation had better effect with the flame duration of 19.10 minutes and fire beight of $35 \mathrm{~cm}$. As for the combustion site temperature, the best result was obtained from $\mathrm{F} 1$ formulation.
\end{abstract}

Keyword: Rocket Stove, Wood Pellet, Sengon Wood, Approriate Technology, Alternative Fuels.

\begin{tabular}{l}
\hline PEMANFAATAN \\
GEKNOLOGI TEPAT
\end{tabular}




\section{PENDAHULUAN}

Teknologi sangatlah di butuhkan untuk kebutuhan pokok sehari-hari. Teknologi digunakan sebagai alat komunikasi, industri, dll. Akan tetapi alokasi teknologi di Indonesia untuk memenuhi kebutuhan teknologi masih belum merata. Hal ini di-sebabkan kurangnya kesadaran masyarakat akan penting teknologi di masa kini.

Seiring perkembanngan zaman, masyarakat Indonesia menciptakan teknologi yang bisa digunakan di berbagai tempat dengan keterbatasan fasilitas seperti listrik atau pun akses jalan yang tidak memadai sehingga teknologi tepat guna (TTG) sangatlah dibutuhkan terutama di desa yang terpencil.

Teknologi tepat guna (TTG) di bidang pertanian pada umumnya digunakan untuk membantu para petani seperti dalam hal budidaya dan panen. Teknologi ini dinilai sangatlah membantu para petani yang memiliki kendala dalam budidaya tanaman karena teknologi tepat guna memiliki kelebihan yaitu harga yang terjangkau, bisa menyesuaikan dengan keadaan lingkungan sekitar, dan mudah di operasikan.

Salah satu teknologi tepat guna yaitu kompor roket adalah kompor tungku yang terbuat dari besi dengan bentuk yang seperti cerobong asap. Aplikasi penggunaan kompor roket akan meningkatkan efisiensi pembakaran dan perpindahan panas secara signifikan. Prinsip kerja kompor roket membutuhkan sedikit kayu bakar tetapi menghasilkan panas yang optimal. Kompor tradisional yang sering disebut juga kompor tiga batu (three stone stove) hanya memiliki efisiensi 5 - $10 \%$ dan dengan sedikit sentuhan keteknikan dapat ditingkatkan efisiensienya dua hingga tiga kali lipat (Barnes, 1994). Karena itu berbagai desain kompor biomassa dengan sentuhan keteknikan telah dikembangkan dengan efisiensi yang baik seperti: kompor roket, TLUD/TLUD stove (Still, 2012), Kompor Gama (Febriansyah et al., 2014), Kompor UB (Yuswansyah et al., 2013),
Kompor Sekam Padi (Simorangkir et al., 2010), anila stove (Alburquerque et al., 2013) dan lain-lain. Berbagai jenis dan tipe kompor biomassa yang dikembangkan dengan prinsip-prinsip keteknikan dapat dilihat pada (Roth et al., 2011).

Bahan bakar adalah kebutuhan pokok yang sangat penting di dunia karena aktivitas manusia membutuhkan bahan bakar untuk transportasi, rumah tangga, dan industri. Ketergantungan akan energi bahan bakar fosil seperti batu bara, minyak bumi, dan gas akan semakin meningkat dari masa ke masa. Pada beberapa dekade mendatang, penggunaan bahan bakar fosil harus dikurangi karena bahan bakar fosil adalah sumber daya yang terbatas dan suatu saat pasti akan habis. Terdapat beberapa jenis bahan bakar yaitu bahan bakar fosil dan biomassa. Pada umumnya manusia menggunakan bahan bakar fosil seperti minyak bumi, gas bumi, dll. Akan tetapi bahan bakar fosil akan habis dengan bertambahnya populasi manusia akibat kebutuhan bahan bakar fosil meningkat. Salah satu penggunaan bahan bakar fosil yaitu gas LPG. Gas LPG diperlukan sebagai bahan bakar untuk kebutuhan rumah tangga, industri, dll.

Biomassa adalah bahan yang berasal dari makhluk hidup, termasuk tanaman, hewan dan mikroba. Menjadikan biomassa sebagai sumber untuk memenuhi berbagai kebutuhan menjadi sangat menarik sebab biomassa merupakan bahan yang dapat diperbaharui. Energi Biomassa bisa menjadi solusi bahan bakar yang selama ini tidak dapat diperbaharui dan mencemari lingkungan hidup. Bahan pembuat energi biomassa dikategorikan menjadi dua jenis, pertama dari hewan yang berupa mikroorganisme ataupun makroorganisme, dan yang kedua berasal dari tumbuhan seperti tanaman sisa pengolahan ataupun hasil panen secara langsung.

Bahan bakar fosil dapat digantikan dengan bahan bakar alternatif yaitu bahan bakar hewani adalah berasal dari bagian hewan seperti kotoran hewan ataupun

\begin{tabular}{lcc}
\hline PEMANFAATAN & TEKNOLOGI TEPAT & NURDI IBNU WIBOWO \\
GUNA KOMPOR & ROKET DENGAN & \\
FORMULASI BAHAN BAKAR PELET KAYU & \\
DAN KAYU SENGON &
\end{tabular}


lemak hewan. Pada umumnya bahan bakar hewani dijadikan biogas dan biodiesel. Bahan bakar nabati terbuat dari tumbuhan yang mati lalu dibuat bahan bakar dengan proses tertentu kemudian dijadikan bahan bakar untuk transportasi, rumah tangga maupun kebutuhan lainnya, contoh dari bahan bakar nabati yaitu, kayu bakar, bioetanol, biodiesel, biobriket.

Kayu merupakan salah satu sumber energi yang diharapkan dapat menggantikan sumber bahan bakar minyak. Namun, memiliki sifat-sifat yang kurang menguntungkan jika langsung dijadikan sebagai bahan bakar antara lain kadar air yang tinggi, mengeluarkan asap, banyak abu, dan nilai kalornya rendah (Zam et al., 2009). Pelet kayu merupakan hasil pemadatan biomassa yang mempunyai tekanan lebih besar dibandingkan briket. Bahan bakar pelet kayu ini berdiameter antara 3-12 $\mathrm{mm}$ dengan panjang antara 6-25 $\mathrm{mm}$. Pelet kayu diproduksi dalam suatu alat dengan mekanisme pemasukan bahan secara kontinu yaitu bahan yang telah dikeringkan, didorong, dan dimampatkan melewati lingkaran baja pada beberapa lubang yang mempunyai ukuran tertentu. kemudian akan patah ketika mencapai panjang yang diinginkan (Ramsay, 1982).

Kebutuhan energi yang semakin tinggi dan pemanfaatan biomassa (limbah) kurang maksimal sehingga perlu dilakukan pemanfaatan biomassa (limbah) menjadi bahan bakar yang potensial penghasil energi, sejalan dengan itu perlu dilakukannya penelitian pemanfaatan kompor roket karena penelitian ini belum pernah dilakukan sebelumnya jadi penelitian ini perlu dilakukan untuk melihat efesiensi kompor roket dibandingkan dengan kompor LPG..

\section{METODE PENELITIAN}

\section{Waktu dan Tempat}

Penelitian ini dilakukan pada bulan Juli 2020 di Serpong Desa Wangun jaya Kec. Cugenang Kab. Cianjur.

\begin{abstract}
Alat dan Bahan
Alat yang digunakan meliputi kompor roket, blower, termometer digital, pematik api, stopwatch, kayu sebagai pengganti penggaris. Bahan yang digunakan antara lain pelet kayu, kayu sengon.
\end{abstract}

\section{Tahapan Penelitian}

\section{Pembuatan kompor roket}

Kompor roket dibuat dari pipa besi dengan panjang $60 \mathrm{~cm}$ dengan ketebalan besi $\mathrm{mm}$ kemudian dibentuk dengan panjang $25 \mathrm{~cm}$, tinggi $35 \mathrm{~cm}$, dan diameter lubang kompor roket $17 \mathrm{~cm}$ dengan tambahan pipa besi untuk masuknya blower dengan diameter lubang $5 \mathrm{~cm}$.

\section{Menyiapkan bahan bakar}

Menyiapkan Bahan bakar kompor roket yaitu pelet kayu dengan ukuran rata rata $1,57 \mathrm{~cm} 3$ dengan berat rata - rata 3 gram/pelet dan kayu sengon yang sudah dipotong dengan ukuran kecil lalu dimasukan ke dalam kompor roket.

\section{Menyalakan kompor roket}

Masing - masing bahan bakar dinyalakan dengan dibakar pemantik api setelah menyala dimasukkan ke dalam kompor roket, kemudian ketika api sudah cukup besar blower dimasukkan kedalam lubang kompor.

4. Hitung berapa lama nyala api, suhu, dan tinggi api

Setelelah api menyala hitung berapa lama nyala api, mengukur suhu tertinggi dalam waktu 90 detik, dan mengukur berapa tinggi api pada setiap bahan bakar yang berbeda.

\section{Metode dan Rancangan Penelitian}

Dalam penelitian ini menggunakan rancangan percobaan dengan metode RSM (response surface methode), Metode response surface adalah sekumpulan teknik matematika dan statistika yang berguna untuk menganalisis permasalahan dimana beberapa variabel independen mempengaruhi variabel respon dan bertujuan untuk mengoptimalkan respon (Montgomery, 2009).

Menurut Trihaditia (2015), metode permukaan respon (RSM) merupakan

\begin{tabular}{lcc}
\hline PEMANFAATAN & TEKNOLOGI TEPAT & NURDI IBNU WIBOWO \\
GUNA KOMPOR & ROKET DENGAN & \\
FORMULASI BAHAN BAKAR PELET KAYU & \\
DAN KAYU SENGON & &
\end{tabular}


suatu strategi percobaan yang berguna jika respon dipengaruhi beberapa faktor dan tujuan percobaan adalah untuk mencari respon optimum dengan cara mencari tempuhan titik tengah dan tempuhan lengan bintang (star arm runs).

Tabel 1. komposisi bahan bakar dari pelet kayu dan kayu sengon.

\begin{tabular}{|c|c|c|c|}
\hline Sample & Pelet Kayu (\%) & Kayu sengon (\%) & Total (\%) \\
\hline F1 & 100 & 0 & 100 \\
\hline F2 & 75 & 25 & 100 \\
\hline F3 & 50 & 50 & 100 \\
\hline $\mathrm{F} 4$ & 25 & 75 & 100 \\
\hline F5 & 0 & 100 & 100 \\
\hline
\end{tabular}

Keterangan : $100 \%=1 \mathrm{~kg} 75 \%=750 \mathrm{gr} 50 \%=500 \mathrm{gr} 25 \%=250$ gr.

\section{Teknik Pengumpulan Data}

1. Pengukuran lama waktu nyala api, pengukuran dilakukan dengan menghitung lama waktunya bahan bakar menyala dimulai dari awal api muncul.

2. Pengukuran suhu tertinggi, pengukuran dimulai ketika api sudah menyala dan suhu dihitung ketika sudah mencapai 90 detik.

3. Pengukuran tinggi api dilakukan dengan cara di beri alat ukur berupa tongkat yang sudah diukur dan diberi tanda pada setiap tingginya.
Teknik Analisis Data

Teknik analisa data menggunakan Software Microsoft Office excel dan Minitab 16, pengujian menggunakan Response surface methodology (RSM) untuk mengetahui seberapa besar pengaruh bahan bakar pelet kayu dan kayu sengon pada kompor roket.

\section{HASIL DAN PEMBAHASAN}

\section{Lama nyala api}

Dalam penelitian ini, data yang diperoleh dari hasil uji bahan bakar kemudian diolah dalam aplikasi minitab16. Hasil pengolahan minitab16 dari parameter lama nyala api tersebut dapat dilihat pada tabel berikut.

Tabel 2. Pengolahan data lama nyala api.

\begin{tabular}{ccccccc}
\hline Std Order & Run Order & Pt Type & Blocks & A & B & LAMA NYALA API \\
\hline 1 & 1 & 1 & 1 & -1.00000 & -1.00000 & 15,22 \\
2 & 2 & 1 & 1 & 1.00000 & -1.00000 & 17,19 \\
3 & 3 & 1 & 1 & -1.00000 & 1.00000 & 19,10 \\
4 & 4 & 1 & 1 & 1.00000 & 1.00000 & 13,55 \\
5 & 5 & -1 & 1 & -1.41421 & 0.00000 & 11,07 \\
6 & 6 & -1 & 1 & 1.41421 & 0.00000 & 15,22 \\
7 & 7 & -1 & 1 & 0.00000 & -1.41421 & 17,19 \\
8 & 8 & -1 & 1 & 0.00000 & 1.41421 & 19,10 \\
9 & 9 & 0 & 1 & 0.00000 & 0.00000 & 13,55 \\
10 & 10 & 0 & 1 & 0.00000 & 0.00000 & 11,07 \\
11 & 11 & 0 & 1 & 0.00000 & 0.00000 & 19,10 \\
12 & 12 & 0 & 1 & 0.00000 & 0.00000 & 15,22 \\
13 & 13 & 0 & 1 & 0.00000 & 0.00000 & 11,07 \\
\hline
\end{tabular}

Sumber : Data primer (Olahan) tahun 2020.

Setelah design penelitian parameter lama nyala dibuat, tahap selanjutnya dilakukan penentuan daerah optimasi digunakan grafik secara contour plot. Maka akan dihasilkan grafik sebagai berikut.

\begin{tabular}{lcc}
\hline PEMANFAATAN & TEKNOLOGI TEPAT & NURDI IBNU WIBOWO \\
GUNA KOMPOR & ROKET DENGAN & \\
FORMULASI BAHAN BAKAR PELET KAYU & \\
DAN KAYU SENGON & &
\end{tabular}




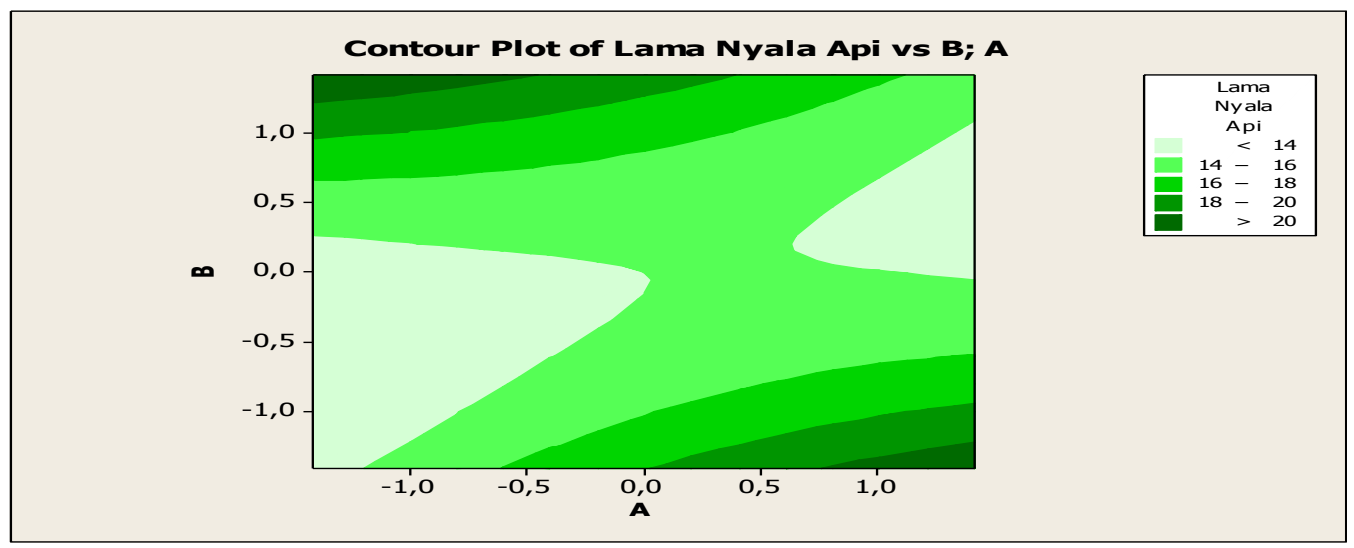

Gambar 1. Contour plot lama nyala api.

Gambar di atas menunjukan bahwa batasan wilayah untuk penentuan nilai optimasi diantara 14 - 20. Penelitian ini didasarkan pada pengujian 5 formulasi berbeda, sehingga didapatkan penentuan wilayah optiamasi berdasarkan nilai ratarata pada tabel berikut.

Tabel 3. Wilayah Optimasi Rata Rata Lama Nyala Api.

\begin{tabular}{cc}
\hline Wilayah Optimasi & Rata-Rata Lama Nyala Api (Menit) \\
\hline 1 & $>20$ \\
2 & $18-20$ \\
3 & $16-18$ \\
4 & $14-16$ \\
5 & $<14$ \\
\hline
\end{tabular}

Untuk mendapatkan nilai optimal dari sampel yang digunakan, maka nilai rata-rata sampel tersebut akan dimasukan kedalam plot wilayah optimasi, sehingga dihasilkan nilai optimasi dari setiap sampel tersebut yang dapat dilihat pada tabel berikut :

Tabel Tabel 4. Nilai Optimasi Rata - rata Lama Nyala Api

\begin{tabular}{ccc}
\hline Sampel & Rata-rata & Wilayah Optimasi \\
\hline F1 (PK 100\%+ KS 0\%) & 15,22 & 4 \\
F2 (PK 25\% + KS 75\%) & 17,19 & 3 \\
F3 (PK 50\%+ KS 50\%) & 19,10 & 2 \\
F4 (PK 75\% + KS 25\%) & 13,55 & 5 \\
F5 (PK 0\%+ KS 100\%) & 11,07 & 5 \\
\hline
\end{tabular}

Sumber: (Data primer olahan tahun 2020).

*Keterangan : PK = Pelet Kayu, KS = Kayu sengon.

Dari tabel tersebut diketaui bahwa sampel F1 mempunyai nilai optimasi 4, dikarenakan rata-rata sampel tersebut berada pada wilayah dengan nilai optimasi 4. F2 mempunyai nilai optimasi 3, dikarenakan rata-rata sampel tersebut berada pada wilayah dengan nilai optimasi 3. F3 mempunyai nilai optimasi 2, dikarenakan rata-rata sampel tersebut berada pada wilayah dengan nilai optimasi 2. F4 mempunyai nilai optimasi 5, dikarenakan rata-rata sampel tersebut berada pada wilayah dengan nilai optimasi 5. F5 mempunyai nilai optimasi 5, dikarenakan rata-rata sampel tersebut berada pada wilayah dengan nilai optimasi 5. Berdasarkan hal tersebut dapat disimpulkan bahwa sampel terbaik untuk optimasi lama nyala api adalah sampel F3, dikarenkan sampel tersebut mempunyai nilai yang paling tinggi. Hal ini diduga pelet kayu yang memiliki tingkat 
kerapatan yang tinggi dan kadar air yang tinggi sehingga membuat nyala api semakin lama, faktor lain yang mendukung karena proses kayu sengon yang terbakar terlebih dahulu yang menyebabkan proses pembakaran yang lama.

Perbedaan lama pembakaran pada pelet kayu dipengaruhi oleh kadar air. Semakin lama pembakaran berarti kadar airnya tinggi, menghasilkan api yang kecil dan jumlah asapnya banyak sesuai dengan penelitian (Rahman, 2011 dalam Winata, 2013) bahwa kadar air sangat mempengaruhi kualitas pelet kayu seperti nilai kalor, pembakaran, kemudahan menyala, daya pembakaran, dan jumlah asap yang dihasilkan selama pembakaran. Sanusi., et al (2010) menambahkan pada kadar air yang tinggi, api pada pelet kayu yang terbakar mula-mula digunakan untuk mengeluarkan air dan setelah semua air dalam pelet kayu habis menguap. setelah itu, massa pelet kayu terbakar.

Menurut (Winata, 2013), pelet kayu memiliki persentase kadar air sebesar $8,54 \%$. Diduga hal inilah yang menjadi penyebab lamanya nyala api pelet kayu pada kompor roket. Sedangkan pada kayu sengon di duga memiliki kadar air yang rendah sehingga menyebabkan kayu cepat habis pada saat dibakar dikompor roket.

Nilai kerapatan merupakan parameter yang digunakan untuk mengetahui kualitas pelet kayu. Semakin tinggi nilai kerapatan pelet kayu dapat memudahkan dalam hal penanganan, penyimpanan dan tranportasi pelet kayu, sehingga dapat menurunkan biaya yang dibutuhkan (Adapa et al., 2009). Kerapatan menunjukkan perbandingan antara massa dan volume pelet kayu. Kerapatan pelet kayu berpengaruh terhadap kualitas. Besar atau kecilnya kerapatan tersebut dipengaruhi oleh ukuran partikel dan kehomogenan bahan penyusun pelet kayu itu sendiri.

Pelet kayu memiliki kerapatan sebesar $1.26 \mathrm{~g} \mathrm{~cm}^{-3}$ yang dimana kerapatan tersebut termasuk kedalam standar yang digunakan beberapa negara (Winata, 2013). Semakin besar kerapatan (density) maka semakin lambat laju pembakaran yang terjadi. Namun, semakin besar kerapatan menyebabkan semakin tinggi pula nilai kalornya (Jamilatun, 2012). Sedangkan pada kayu sengon diduga memiliki tingkat kerapatan yang rendah sehingga menyebabkan kayu cepat habis pada saat dibakar dikompor roket.

Kayu sengon memiliki tingkat kerapatan yang rendah yaitu $0.31 \mathrm{~g} / \mathrm{cm}^{3}$ (Sadiyo et al., 2017) dan kadar air 8,1\% (Satmoko et al., 2013). Hal ini diduga kerapatan dan kadar air kayu sengonlah yang mempengaruhi api menjadi cepat padam pada kompor roket.

\section{Tinggi api}

Hasil pengolahan minitab16 dari parameter tinggi api tersebut dapat dilihat pada table berikut.

Tabel 5. Pengolahan data tinggi api.

\begin{tabular}{ccccccc}
\hline StdOrder & RunOrder & PtType & Blocks & A & B & TINGGI API \\
\hline 1 & 1 & 1 & 1 & -1.00000 & -1.00000 & 25 \\
2 & 2 & 1 & 1 & 1.00000 & -1.00000 & 30 \\
3 & 3 & 1 & 1 & -1.00000 & 1.00000 & 25 \\
4 & 4 & 1 & 1 & 1.00000 & 1.00000 & 20 \\
5 & 5 & -1 & 1 & -1.41421 & 0.00000 & 15 \\
6 & 6 & -1 & 1 & 1.41421 & 0.00000 & 25 \\
7 & 7 & -1 & 1 & 0.00000 & -1.41421 & 30 \\
8 & 8 & -1 & 1 & 0.00000 & 1.41421 & 25 \\
9 & 9 & 0 & 1 & 0.00000 & 0.00000 & 20 \\
10 & 10 & 0 & 1 & 0.00000 & 0.00000 & 15 \\
11 & 11 & 0 & 1 & 0.00000 & 0.00000 & 35 \\
12 & 12 & 0 & 1 & 0.00000 & 0.00000 & 25 \\
13 & 13 & 0 & 1 & 0.00000 & 0.00000 & 15
\end{tabular}

Sumber : Data primer (Olahan) tahun 2020.

\section{PEMANFAATAN TEKNOLOGI TEPAT


Setelah design penelitian parameter tinggi api dibuat, tahap selanjutnya dilakukan penentuan daerah optimasi digunakan grafik secara contour plot. Maka akan dihasilkan grafik sebagai berikut.

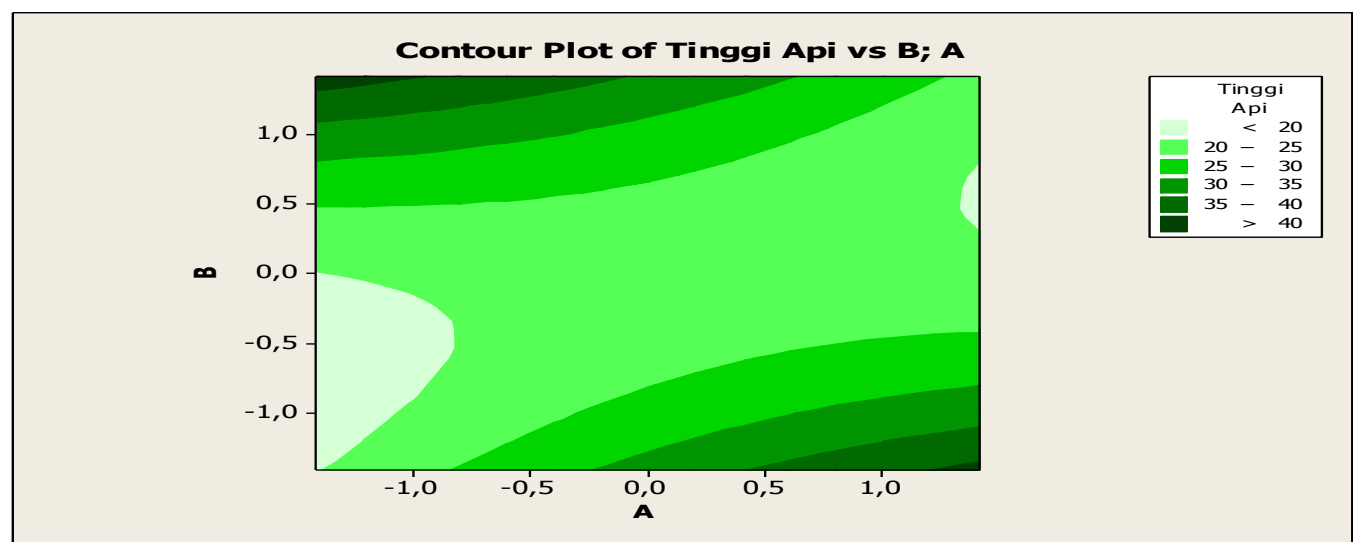

Gambar 2. Contour plot tinggi api.

1. Gambar di atas menunjukan bahwa batasan wilayah untuk penentuan nilai optimasi diantara 20 - 40. Penelitian ini didasarkan pada pengujian 5 formulasi berbeda, sehingga didapatkan penentuan wilayah optiamasi berdasarkan nilai rata-rata pada tabel berikut.

Tabel 6. Wilayah Optimasi Rata - rata Tinggi Api.

\begin{tabular}{cc}
\hline Wilayah Optimasi & Rata-Rata Tinggi Api (CM) \\
\hline 1 & $>40$ \\
2 & $35-40$ \\
3 & $30-35$ \\
4 & $25-30$ \\
5 & $20-25$ \\
6 & $<20$ \\
\hline
\end{tabular}

Untuk mendapatkan nilai optimal dari sampel yang digunakan, maka nilai rata-rata sampel tersebut akan dimasukan kedalam plot wilayah optimasi, sehingga dihasilkan nilai optimasi dari setiap sampel tersebut yang dapat dilihat pada tabel berikut :

Tabel 7. Tabel Nilai Optimasi Rata - rata Tinggi Api

\begin{tabular}{ccc}
\hline Sampel & Rata-rata & Wilayah Optimasi \\
\hline F1 (PK 100\%+ KS 0\%) & 25 & 4 \\
F2 (PK 25\%+ KS 75\%) & 30 & 3 \\
F3 (PK 50\%+ KS 50\%) & 35 & 2 \\
F4 (PK 75\%+ KS 25\%) & 20 & 5 \\
F5 (PK 0\%+ KS 100\%) & 15 & 6 \\
\hline
\end{tabular}

Sumber: (Data primer olahan tahun 2020)

*Keterangan : PK = Pelet Kayu, KS = Kayu Sengon

2. Dari tabel tersebut diketaui bahwa sampel F1 mempunyai nilai optimasi 4, dikarenakan rata-rata sampel tersebut berada pada wilayah dengan nilai optimasi 4. F2 mempunyai nilai optimasi 3, dikarenakan rata-rata sampel tersebut berada pada wilayah dengan nilai optimasi 3. F3 mempunyai nilai optimasi 2, dikarenakan rata-rata sampel tersebut berada pada wilayah dengan nilai optimasi 2. F4 mempunyai nilai optimasi 5, dikarenakan rata-rata sampel tersebut berada pada wilayah 
dengan nilai optimasi 5. F5 mempunyai nilai optimasi 6, dikarenakan rata-rata sampel tersebut berada pada wilayah dengan nilai optimasi 6. Berdasarkan hal tersebut dapat disimpulkan bahwa sampel terbaik untuk optimasi tinggi api adalah sampel F3, dikarenkan sampel tersebut mempunyai nilai yang paling tinggi. Hal ini diduga kombinasi kayu sengon dan pelet kayu membentuk celah sehingga sirkulasi udara membantu pembakaran optimal. Nilai kalor dan tingkat kerapatan pada pelet kayu diduga dapat mempengaruhi tinggi api karena api yang dihasilkan oleh pelet kayu sangatlah bagus.
Pelet kayu memiliki kerapatan sebesar $1.26 \mathrm{~g} \mathrm{~cm}^{-3}$ dimana kerapatan tersebut termasuk ke dalam standar yang digunakan beberapa negara (Winata, 2013). Semakin besar kerapatan (density) maka semakin lambat laju pembakaran yang terjadi. Namun, semakin besar kerapatan menyebabkan semakin tinggi pula nilai kalornya (Jamilatun, 2012). Sedangkan pada kayu sengon diduga memiliki tingkat kerapatan yang rendah sehingga menyebabkan kayu cepat habis pada saat dibakar dikompor roket. Nilai kalor pada pelet kayu menurut Adrian et al., (2015) yaitu kurang lebih sebesar 4029 $\mathrm{Kkal} / \mathrm{kg}$ - $4106 \mathrm{Kkal} / \mathrm{kg}$.

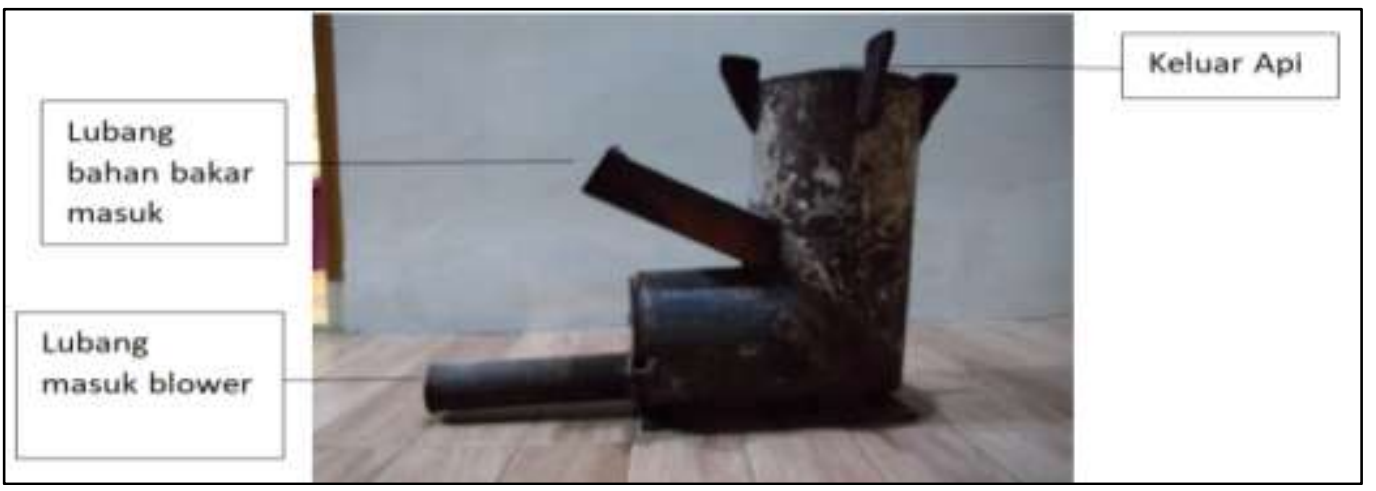

Gambar 3. Bentuk kompor roket.

3. Bentuk kompor roket diduga berpengaruh pada pada tingginya api karena angin yang ditiupkan oleh blower berfokus pada satu arah sehingga bahan bakar yang terbakar menghasilkan api yang optimal. Menurut Makay, (2010) kompor roket bekerja dengan menarik udara dingin dengan volume besar ke atas bahan bakar yang terbakar. Pasokan oksigen dalam jumlah besar ini memudahkan pembakaran partikel bahan bakar yang lebih sempurna yang tidak terbakar di udara sebagai asap. Diduga dengan adanya blower mampu mengeluarkan udara ke dalam kompor roket sehingga mengoptimalkan tinggi api pada bahan bakar tersebut.

\section{Suhu Ruang Bakar}

Hasil pengolahan minitab16 dari parameter suhu ruang tersebut dapat dilihat pada tabel berikut. 
Tabel 8. Pengolahan data suhu ruang bakar.

\begin{tabular}{ccccccc}
\hline Std Order & Run Order & Pt Type & Blocks & A & B & Suhu Ruang Bakar \\
\hline 1 & 1 & 1 & 1 & -1.00000 & -1.00000 & 87,2 \\
2 & 2 & 1 & 1 & 1.00000 & -1.00000 & 67,1 \\
3 & 3 & 1 & 1 & -1.00000 & 1.00000 & 65,5 \\
4 & 4 & 1 & 1 & 1.00000 & 1.00000 & 69,8 \\
5 & 5 & -1 & 1 & -1.41421 & 0.00000 & 67,5 \\
6 & 6 & -1 & 1 & 1.41421 & 0.00000 & 87,2 \\
7 & 7 & -1 & 1 & 0.00000 & -1.41421 & 67,1 \\
8 & 8 & -1 & 1 & 0.00000 & 1.41421 & 65,5 \\
9 & 9 & 0 & 1 & 0.00000 & 0.00000 & 69,8 \\
10 & 10 & 0 & 1 & 0.00000 & 0.00000 & 67,5 \\
11 & 11 & 0 & 1 & 0.00000 & 0.00000 & 87,2 \\
12 & 12 & 0 & 1 & 0.00000 & 0.00000 & 67,5 \\
13 & 13 & 0 & 1 & 0.00000 & 0.00000 & 65,5 \\
\hline
\end{tabular}

Sumber : Data primer (Olahan) tahun 2020.

Setelah design penelitian parameter suhu ruang dibuat, tahap selanjutnya dilakukan penentuan daerah optimasi

digunakan grafik secara contour plot. Maka akan dihasilkan grafik sebagai berikut.

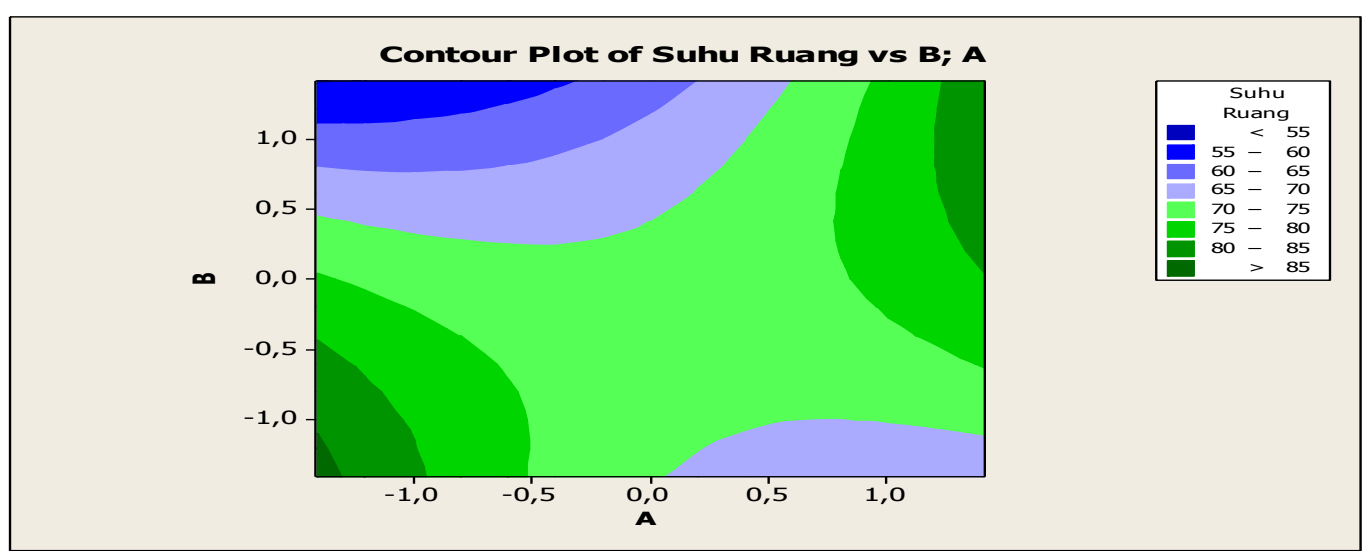

Gambar 4. Contour plot suhu ruang bakar.

Gambar di atas menunjukan bahwa batasan wilayah untuk penentuan nilai optimasi diantara 55 - 85. Penelitian ini didasarkan pada pengujian 5 formulasi berbeda, sehingga didapatkan penentuan wilayah optiamasi berdasarkan nilai ratarata pada tabel berikut :

Tabel 9. Wilayah Optimasi Rata - rata Suhu Ruang Bakar.

\begin{tabular}{cc}
\hline Wilayah Optimasi & Rata-Rata Suhu Ruang Bakar $\left({ }^{\circ} \mathbf{C}\right)$ \\
\hline 1 & $85>$ \\
2 & $80-85$ \\
3 & $75-80$ \\
4 & $70-75$ \\
5 & $65-70$ \\
6 & $60-65$ \\
7 & $55-60$ \\
8 & $<55$ \\
\hline
\end{tabular}

Untuk mendapatkan nilai optimal dari sampel yang digunakan, maka nilai rata-rata sampel tersebut akan dimasukan ke dalam plot wilayah optimasi, sehingga dihasilkan nilai optimasi dari setiap sampel tersebut yang dapat dilihat pada tabel berikut : 
Tabel 10. Nilai optimasi rata - rata suhu ruang bakar.

\begin{tabular}{lcc}
\hline Sampel & Rata-rata & Wilayah Optimasi \\
\hline F1 (PK 100\% + KS 0\%) & 87,2 & 1 \\
F2 (PK 25\%+ KS 75\%) & 67,1 & 5 \\
F3 (PK 50\%+ KS 50\%) & 65,5 & 5 \\
F4 (PK 75\%+ KS 25\%) & 69,8 & 5 \\
F5 (PK 0\%+ KS 100\%) & 65,5 & 5 \\
\hline
\end{tabular}

Sumber: (Data primer olahan tahun 2020)

*Keterangan $: \mathrm{PK}=$ pelet kayu, $\mathrm{KS}=$ Kayu Sengon.

Dari tabel tersebut diketaui bahwa sampel F1 mempunyai nilai optimasi 1, dikarenakan rata-rata sampel tersebut berada pada wilayah dengan nilai optimasi 1. F2 mempunyai nilai optimasi 5, dikarenakan rata-rata sampel tersebut berada pada wilayah dengan nilai optimasi 5. F3 mempunyai nilai optimasi 5, dikarenakan rata-rata sampel tersebut berada pada wilayah dengan nilai optimasi 5. F4 mempunyai nilai optimasi 5, dikarenakan rata-rata sampel tersebut berada pada wilayah dengan nilai optimasi 5. F5 mempunyai nilai optimasi 5, dikarenakan rata-rata sampel tersebut berada pada wilayah dengan nilai optimasi 5. Berdasarkan hal tersebut dapat disimpulkan bahwa sampel terbaik untuk optimasi suhu ruang adalah sampel F1, dikarenkan sampel tersebut mempunyai nilai yang paling tinggi. Hal ini diduga pada saat pembakaran, pembakaran pelet kayu lebih sempurna dibanding dengan kayu sengon, karena nilai kalor pada pelet kayu lebih besar. Faktor lain yaitu ukuran pelet kayu yang kecil menyebabkan cepat merambatnya api ke seluruh pelet kayu berbeda dengan kayu sengon yang memiliki ukuran yang besar sehingga penyebaran api sedikit lama. Menurut Sudiro, (2014), Partikel yang lebih kecil ukuranya akan lebih mudah dan cepat terbakar.

Menurut Amirta, (2018) Di dalam proses ini bahan baku akan ditekan melalui lubang-lubang yang memiliki ukuran yang dibutuhkan (biasanya berdiameter $6 \mathrm{~mm}$, kadang-kadang $8 \mathrm{~mm}$ atau lebih besar)

Nilai kalor merupakan salah satu parameter penting dalam pemilihan bahan bakar padat seperti pelet kayu (Liliana, W. 2010 dalam Hasanuddin et al., 2012).
Kalor yang semakin tinggi menunjukan kualitas bahan bakar yang semakin baik, kalor dipengaruhi oleh kadar air dan kerapatan, nilai kalor berbanding terbalik dengan kadar air. Semakin tinggi kadar air pada suatu bahan bakar maka kalor yang dihasilkan akan semakin rendah (Rahman, 2011 dalam Winata, 2013).

Nilai kalor pada pelet kayu menurut Adrian et al., (2015) yaitu kurang lebih sebesar $4029 \mathrm{Kkal} / \mathrm{kg}$ - 4106 $\mathrm{Kkal} / \mathrm{kg}$, sedangkan nilai kalor pada kayu sengon menurut Cahyono et al., (2008) memiliki nilai kalor $3.948 \mathrm{Kkal} / \mathrm{kg}$. Diduga faktor ini yang menyebabkan cepatnya panas pada kompor roket

\section{KESIMPULAN}

Dari penelitian ini dapat di simpulkan sebagai berikut :

1. Lama pembakaran terbaik pada perlakuan F3 yaitu campuran pelet kayu 500gr dan kayu sengon 500gr selama 19,10 menit. Hal ini di karenakan pelet kayu memiliki kerapatan dan kadar air yang tinggi dibandingkan dengan perlakuan F5 yaitu kayu sengon $1 \mathrm{~kg}$ selama 11,07 menit.

2. Tinggi api terbaik pada perlakuan F3 yaitu campuran pelet kayu 500gr dan kayu sengon $500 \mathrm{gr}$ selama $35 \mathrm{~cm}$. Hal ini dikarenakan pelet kayu yang memiliki nilai kalor yang tinggi dibanding dengan kayu sengon sehingga menyebabkan nyala api yang sempurna dan menghasilkan tinggi api yang bagus.

3. Suhu terbaik pada perlakuan F1 yaitu pelet kayu $1 \mathrm{~kg}$ sebesar $87,2^{\circ} \mathrm{C}$ pada suhu ruang di dalam kompor roket

\begin{tabular}{lcc}
\hline PEMANFAATAN & TEKNOLOGI TEPAT & NURDI IBNU WIBOWO \\
GUNA KOMPOR & ROKET DENGAN & \\
FORMULASI BAHAN BAKAR PELET KAYU & \\
DAN KAYU SENGON & &
\end{tabular}


selama 90 detik. Suhu terendah pada perlakuan F3 yaitu pelet kayu 500gr dan kayu sengon 500 gr sebesar $65,5^{\circ} \mathrm{C}$ pada suhu ruang di dalam kompor roket selama 90 detik. Hal ini dikarenakan nilai kalor dan tingkat kerapatan yang bagus serta ukuran yang kecil menghasilkan panas yang merata dan suhu yang tinggi

4. Dari semua perlakuan yang telah dilakukan didapatkan hasil dimana F3 sebagai bahan bakar yang efisien, hal ini dikarenakan F3 memiliki lama nyala api yang paling lama dan tinggi api yang tinggi. Sehingga dapat di simpulkan bahwa F3 bahan bakar yang efisien.

\section{DAFTAR PUSTAKA}

Adapa P., Tabil L., Schoenau G. 2009. Compression Characteristics of Selected Ground Agricultural Biomass. Agricultural Engineering International: the CIGR Ejournal. Manuscript 1347. Vol. XI.

Alburquerque, J. A., Salazar, P., Barrón, V., Torrent, J., Del Campillo, M. D. C., Gallardo, A., \& Villar, R. 2013. Enhanced wheat yield by biochar addition under different mineral fertilization levels. Agronomy for Sustainable Development. 33(3): 475484.

Ari Adrian, \& Oktorini, R. S. Y. 2015. Karakteristik Wood pellet Dari Limbah Kayu Karet (Hevea brazilliensis Muell. Arg) Sebagai Alternatif Sumber Energi Terbarukan. 4(12), 10-14.

Baker, S., Scharstein, D., Roth, S., Black, M. J., \& Szeliski, R. 2011. A Database and Evaluation Methodology for Optical Flow. A Database and Evaluation Methodology for Optical Flow, 1-31. https://doi.org/10.1007/s11263010-0390-2

Barnes, V. S. R. K. V. K. C. L. 1994. No Transition Metal Chemistry of Main Group Hydrazides, 9. Platinum Complexes of Diphosphanylhydrazides R2PN(Me)N(Me)PR2 $\cdot$ PtCl2 $(\mathrm{R}=$
$\mathrm{OPh}$, o-OC6H4CH2CHCH2)Title.

Batubara, B., \& Jamilatun, S. 2012. SifatSifat Penyalaan dan Pembakaran Briket Biomassa. Briket Batubara dan Arang Kayu. Sifat-Sifat Penyalaan Dan Pembakaran Briket Biomassa, Briket Batubara Dan Arang Kayu. 2(2): 37-40.

Cahyono, T. D., Coto, Z., \& Febrianto, F. (2008). Analisis Nilai Kalor Dan Kelayakan Ekonomis Kayu Sebagai Bahan Bakar. Forum Pascasarjana, 31(2):105-116.

Eza Yolan Yuswansyah1, Agus Haryanto, Budianto Lanya, T. 2013. Potensi Penerimaan Masyarakat Terbadap Kompor Biomassa Ub-03 [ The Potential Of Community Acceptance On Ub-03 Biomass Stove ]. 2(1): 77-84

Febriansyah, H., Agus, A., \& Suryopratomo, K. 2014. Gama Stove: Biomass Stove for Palm Kernel Shells in Indonesia. Energy Procedia.47:123-132.

Hady, M., Zam, A., \& Putranto, B.2009. Karakteristik Pellet Kayu Gmelina (Gmelina arborea Roxb). 04(11): 1-7.

Hasanuddin dan lahay, i. D. 2012. Pembuatan Biopelet Ampas Kelapa Sebagai Energi Bahan Bakar Alternatif Pengganti Minyak Tanah Ramah Lingkungan. Laporan Penelitian. Jurusan Teknik Industri Fakultas Teknik Universitas Negeri Gorontalo. Gorontalo.

Montgomery, N. S. M. P. Design and Analysis of experiments. New York: John Wiley And Sons. Inc

Mochamad Ervando Among Satmoko, Danang Dwi Saputro, A. B. 2013. Karakterisasi Briket Dari Limbah Pengolahan Kayu Sengon Dengan Metode Cetak Panas. 2(1).

Ramsay, S. W. 1982. Energy from forest biomass: XVII IUFRO World Congress Energy Group proceedings. 279.

Rudianto Amirta. 2018. Pellet kayu (Kiswanto, ed.).

Sadiyo, S., Elsa, N., \& Pratiwi, S. 2017. Nilai Kekuatan Tumpu Baut pada Empat Jenis Kayu Rakyat 
Indonesia. Jurnal Teknik Sipil: 24(2):153-158.

Sanusi, dkk. 2010. Karakteristik Pellet Kayu Sengon. Laporan Penelitian Fakultas Kehutanan Universitas Hasanuddin. Makasar.

Simorangkir, H., Darmasetiawan, H., \& Yani, A. 2010. Kajian Efesiensi Energi Tungku Sekam Berdasarkan Jumlah , Bentu dan Ukuran Sirip yang Dipasang. 241-250.

Still, D. K. 2012. Sbir / Sttr Final Scientific/Technical Report Cover Page Doe Award Number: Recipient: Asat, Incorporated . Project Title: Improved Biomass Cooking Stoves and Improved Stove Emission Equipment Principal Investigator: Asatinc . Final Scientific Technical Report Executive. (4). 15.

Sudiro dan Suroto, S. 2014. Pengaruh Komposisi Dan Ukuran Serbuk Briket Yang Terbuat Dari
Batubara Dan Jerami Padi Terhadap Karakteristik Pembakaran. Sainstech Politeknik Indonusa Surakarta, 2(2): 131.

Tim Makay. 2010. So, How Does a Rocket Stove Work. https://modernsurvivalonline.com /how-rocket-stoves-work/. 21 Juli 2020, 20.00 WIB.

Trihaditia, R. 2015. Penentuan Formulasi Optimum pada Pembuatan Minuman Fungsional Rambut Jagung dengan Penambahan Madu dan Jeruk Nipis Menggunakan Metode RSM (Response Surface Method). Tesis. Fakultas Teknologi Pangan Universitas Pasundan. Bandung.

Tim Makay. 2010. So, How Does a Rocket Stove Work. https://modernsurvivalonline.com /how-rocket-stoves-work/. 21 Juli 2020, 20.00 WIB 